\title{
Predictors of loss to follow up among patients with type 2 diabetes mellitus attending a private not for profit urban diabetes clinic in Uganda - a descriptive retrospective study
}

Salome Tino ${ }^{\text {** }}$, Clara Wekesa ${ }^{1}$, Onesmus Kamacooko ${ }^{1}$, Anthony Makhoba², Raymond Mwebaze ${ }^{2}$, Samuel Bengo ', Rose Nabwato', Aisha Kigongo', Edward Ddumba², Billy N. Mayanja', Pontiano Kaleebu' ${ }^{1,3}$, Rob Newton ${ }^{1,4}$ and Moffat Nyerinda ${ }^{1,3}$

\begin{abstract}
Background: Although the prevalence of type 2 diabetes mellitus is increasing in Uganda, data on loss to follow up (LTFU) of patients in care is scanty. We aimed to estimate proportions of patients LTFU and document associated factors among patients attending a private not for profit urban diabetes clinic in Uganda.

Methods: We conducted a descriptive retrospective study between March and May 2017. We reviewed 1818 outpatient medical records of adults diagnosed with type 2 diabetes mellitus registered between July 2003 and September 2016 at St. Francis Hospital - Nsambya Diabetes clinic in Uganda. Data was extracted on: patients' registration dates, demographics, socioeconomic status, smoking, glycaemic control, type of treatment, diabetes mellitus complications and last follow-up clinic visit. LTFU was defined as missing collecting medication for six months or more from the date of last clinic visit, excluding situations of death or referral to another clinic. We used Kaplan-Meier technique to estimate time to defaulting medical care after initial registration, log-rank test to test the significance of observed differences between groups. Cox proportional hazards regression model was used to determine predictors of patients' LTFU rates in hazard ratios (HRs).

Results: Between July 2003 and September 2016, one thousand eight hundred eighteen patients with type 2 diabetes mellitus were followed for 4847.1 person-years. Majority of patients were female 1066/1818 (59\%) and 1317/1818 (72\%) had poor glycaemic control. Over the 13 years, 1690/1818 (93\%) patients were LTFU, giving a LTFU rate of 34.9 patients per 100 person-years (95\%Cl: 33.2-36.6). LTFU was significantly higher among males, younger patients (< 45 years), smokers, patients on dual therapy, lower socioeconomic status, and those with diabetes complications like neuropathy and nephropathy.
\end{abstract}

Conclusion: We found high proportions of patients LTFU in this diabetes clinic which warrants intervention studies targeting the identified risk factors and strengthening follow up of patients.

Keywords: Type 2 diabetes mellitus, Lost to follow up, Diabetes clinic, Uganda, Predictors

\footnotetext{
* Correspondence: tino.salome@mrcuganda.org; tinosalome@yahoo.co.uk

${ }^{1}$ MRC/UVRI and LSHTM Uganda Research Unit, P.O. Box 49, Entebbe, Uganda

Full list of author information is available at the end of the article
}

(c) The Author(s). 2019 Open Access This article is distributed under the terms of the Creative Commons Attribution 4.0 International License (http://creativecommons.org/licenses/by/4.0/), which permits unrestricted use, distribution, and reproduction in any medium, provided you give appropriate credit to the original author(s) and the source, provide a link to the Creative Commons license, and indicate if changes were made. The Creative Commons Public Domain Dedication waiver (http://creativecommons.org/publicdomain/zero/1.0/) applies to the data made available in this article, unless otherwise stated. 


\section{Background}

Globally, 422 million adults aged over 18 years were living with diabetes mellitus in 2014 and this is expected to rise to 552 million by 2030 [1]. Type 2 diabetes mellitus is becoming epidemic in nearly every population and it's proposed that without effective prevention and control programmes, the prevalence will continue to increase globally most likely as a result of rising overweight and obesity rates, lifestyle, dietary changes, and an ageing population [2]. This condition is not only affecting developed countries but it's rising rapidly in low and middle income countries $[3,4]$. However, the health systems in low and middle income countries have mainly targeted healthcare provision for acute episodic conditions and not medical care for chronic conditions. In Uganda the prevalence of diabetes mellitus is estimated at $10.1 \%$ while impaired glucose tolerance is estimated at $13.8 \%$ [5].

Several studies conducted in developed countries have shown that continuous care and greater compliance to clinic appointments is associated with good glycaemic control, decreased probability of diabetes-related complications and mortality because patients who stop treatment miss opportunities for detecting complications and treatment adjustments [6-11]. However, in other developed countries the rates of patients dropping out from diabetes care are high and varied: 5.4 and 18\% in Malaysia [12], 5.5\% in German [13], 12\% in Nashville-Tennessee [14] and 46\% in Canada [15]. Quantitative studies done in the United Kingdom and United States showed that overweight or obesity, hypertension, presence of neuropathy, poor glycaemic control, older age, low income, smoking, rural residence and male sex were associated with clinic follow-up non-attendance $[14,16-21]$. Another study revealed that men, not being on insulin or antiplatelet agents, having higher $\mathrm{HbA1c}$, higher Low Density Lipoprotein Cholesterol (LDL-C) and having complications of diabetes mellitus were associated with follow-up non-attendance. Older age and higher LDL$\mathrm{C}$ were also associated with higher mortality. Reports from Africa on LTFU are limited, but one study conducted in Kenya reported a dropout rate of $31 \%$ among registered patients with diabetes mellitus in a primary health care program [22]. In a recent systematic review of factors affecting follow-up non-attendance, 83 factors were classified into three categories. These included patient factors (e.g. mental state, alcohol and tobacco use, etc.); disease and medication factors (e.g. poor disease control); and health care provider factors (e.g. scheduling, health provider characteristics, doctor-patient relationships [23]. In Uganda, no study has estimated the LTFU among patients with diabetes mellitus and we theorize that rates of LTFU are high and its predictors are varied. Therefore, this descriptive retrospective study of clinic medical records through chart reviews was undertaken to estimate the LTFU rates and document the associated factors since this is an important determinant of poor glycaemic control long-term outcomes. The findings from this study will inform policy makers and program managers to address the challenges of patient LTFU as well as provide a base line report for interventions aimed at reducing LTFU in the management of diabetes mellitus.

\section{Methods}

\section{Study design, setting and population}

This was a descriptive retrospective study of 1818 selected medical records of adult patients with diabetes mellitus who were registered in the diabetes clinic at St. Francis Hospital Nsambya in Kampala-Uganda, which is a private not for profit facility [24]. The hospital conducts a diabetes mellitus clinic that operates once a week serving an average of 60 patients on each clinic day. In the diabetes clinic, all patients receive diabetes mellitus health education offered by trained diabetes nurses and fasting blood glucose measurements prior to being reviewed by the doctors [25]. The study population comprised of patients with type two diabetes mellitus who were registered at the clinic between July 2003 and September 2016. The charts were reviewed by a medical doctor, clinical officer and registered nurses for sociodemographic characteristics, date of registration, date of last clinic visit and clinical outcomes using a data collection guide. Patients whose paper clinic records files could not be located, those with missing information, transferred out or recorded as dead, type 1 diabetes mellitus, gestational diabetes were excluded.

\section{Definition of variables}

LTFU: Patients were considered LTFU if they had missed collecting medication for six or more consecutive months from the date they last visited the clinic and retention in medical care considered as continuous follow-up visits to the same health-care service to seek treatment for the same episode of illness [26]. Transfer to other facilities or death of a patient were not regarded as LTFU.

Different treatment options were defined as follows: Life style alone was defined as non-pharmacological treatment involving changes in diet and increased exercise; monotherapy as use of metformin alone or any other single oral hypoglycemic; dual therapy as a combination of metformin plus another oral hypoglycemic or metformin plus insulin; triple therapy as a combination of metformin plus two other oral hypoglycemic agents or metformin plus another oral hypoglycemic and insulin; and combination injection therapy was defined as use of different insulin regimens.

Hypertension: This was defined as systolic blood pressure $\geq 140 \mathrm{mmHg}$ and/or diastolic pressure of $\geq 90$ $\mathrm{mmHg}$.

Optimal glycaemic control: This was defined as preprandial glucose $4.4-7.2 \mathrm{mmol} / \mathrm{L}$ measured as an average of the last 3 readings on 3 separate clinic visits among 
patients with diabetes mellitus under care. Fasting glucose reading of $>7.2 \mathrm{mmol} / \mathrm{L}$ was considered as uncontrolled glycaemia.

Socioeconomic status (SES) was defined based on house hold assets. Upper SES defined as living in a house with electricity or solar power supply, piped water, flushing toilet and kitchen inside; Middle SES as living in a house with at least one but not all the utilities above; Lower SES as living in a house without the above and not mud or wattle and not grass hatched; Poor SES as living in mud and wattle grass hatched house and none of the amenities above.

For residence we used the host hospital's definations; urban was defined as living within $1 \mathrm{~km}(\mathrm{~km})$ of a town council; Peri-urban as living within $1 \mathrm{~km}$ of a shop selling soft drinks and Rural as living more than $1 \mathrm{~km}$ of a shop selling soft drinks.

\section{Data source and collection}

The data for this research was secondary data collected routinely in the hospital for patients' clinical monitoring and evaluation purposes. Data was collected and entered into a Microsoft Excel 2010 database (Microsoft Corp., Redmond, WA), checked for consistencies and completeness, and then exported to STATA 13.1 (Stata Corp, College Station, TX, USA) for further management and analysis. Data collected for this review included demographics, date of first registration, date of last clinic visit, past medical history, glycaemic levels, medication use, complications of diabetes and biophysical measurements. The primary outcome variable was LTFU from the diabetes mellitus care after initiation of treatment, confirmed by reviewing medical records at the hospital.

\section{Statistical analysis}

The patients' characteristics were described in terms of mean, median or percentage as appropriate. The Kaplan-Meier technique was used to estimate time to defaulting medical care after initial registration into the diabetes clinic, while the log-rank test was used to test the significance of observed differences between groups. The Cox proportional hazards regression model was used to determine predictors of patients' retention and defaulting rates expressed as estimated hazard ratios (HRs) with their corresponding 95\% confidence intervals (CIs). At the unadjusted modelling level, variables which gave a Log- Likelihood ratio tests (LRTs) $p$-value less than or equal to 0.1 were considered for the adjusted model. At the multivariable analysis, variables that were earlier dropped, were again added onto the model one by one to look at the effect until the final model was obtained. Variables whose p-value was less than 0.05 level were considered to be independent risk factors of LTFU in this study. We considered age and sex as priori confounders.

\section{Results}

Between July 2003 and September 2016, a total of 2518 diabetes mellitus patients were registered in the diabetes clinic of St. Francis Hospital Nsambya in Kampala, Uganda. We excluded 700 records due to missing files, files with missing information, type 1 diabetes mellitus, gestational diabetes mellitus, deaths and transfers out (Fig. 1). The 1818 patients included in the study were followed for a total of 4847.1 person-years, with the longest individual follow up being 14.2 years. The majority of the patients were females $59 \%(n=$ 1066), $75 \%$ were aged more than 45 years old $(n=1364)$, $89 \%$ resided in peri-urban and urban areas $(n=1611), 76 \%$ belonged to middle and upper social class $(n=1328)$, about $10 \%$ were smokers $(n=190), 26 \%$ were alcohol consumers $(n=466), 18 \%$ had retinopathy $(n=330), 66 \%$ had uncontrolled hypertention $(n=1199)$ and $72 \%(n=1317)$ had poor glycaemic control (Table 1).

Over the 13 years follow up, 93\% $(n=1690)$ of the patients were lost to follow up, with $52 \%(n=945)$ of the LTFU occurring within the first year after registration in the diabetes clinic. The median time to LTFU was 11 months; Interquartile range 5.9 to 45.0 months. The estimated LTFU rate was 34.9 per 100 person-years (95\% CI: 33.2 - 36.6). In the multivariate analysis, male patients were more likely to be LTFU than females (adjusted Hazard Ratio, aHR 1.17 [95\% CI: 1.06-1.30]). Patients aged $45-64$ years (aHR 0.83; 95\% CI: 0.74-0.94) and those above 64 years (aHR 0.78; 95\% CI: 0.67-0.90) were more likely to be retained in care than the younger age group of 44 years and below. Retention in diabetes mellitus care was also associated with middle socioeconomic status (aHR 0.83; 95\% CI: 0.74-0.94) and upper social economic status (aHR 0.83; 95\% CI: 0.73-0.95) compared to lower socioeconomic status, being a nonsmoker (aHR 0.82; 95\% CI: 0.70-0.96) and being on dual therapy (aHR 0.78; 95\% CI: 0.70-0.86). Loss to follow up from care was associated with diabetes mellitus complications such as neuropathy (aHR 1.38; 95\% CI: $1.24-$ 1.54), nephropathy (aHR 1.76; 95\% CI: 1.41-2.20), being on triple therapy (aHR of 1.30; 95\% CI: 1.03-1.63). Patients on lifestyle control alone and combination injection therapy were few and were not associated with loss to follow up. Residence, education level, alcohol intake, lifestyle therapy alone, combination injection therapy, complications of diabetes mellitus such as hypertension, retinopathy, macroangiopathy (coronary artery disease, cerebral vascular disease, peripheral vascular disease), diabetic foot, having hypoglycaemic episodes and uncontrolled glycaemia were not independently associated with LTFU (Table 2). 


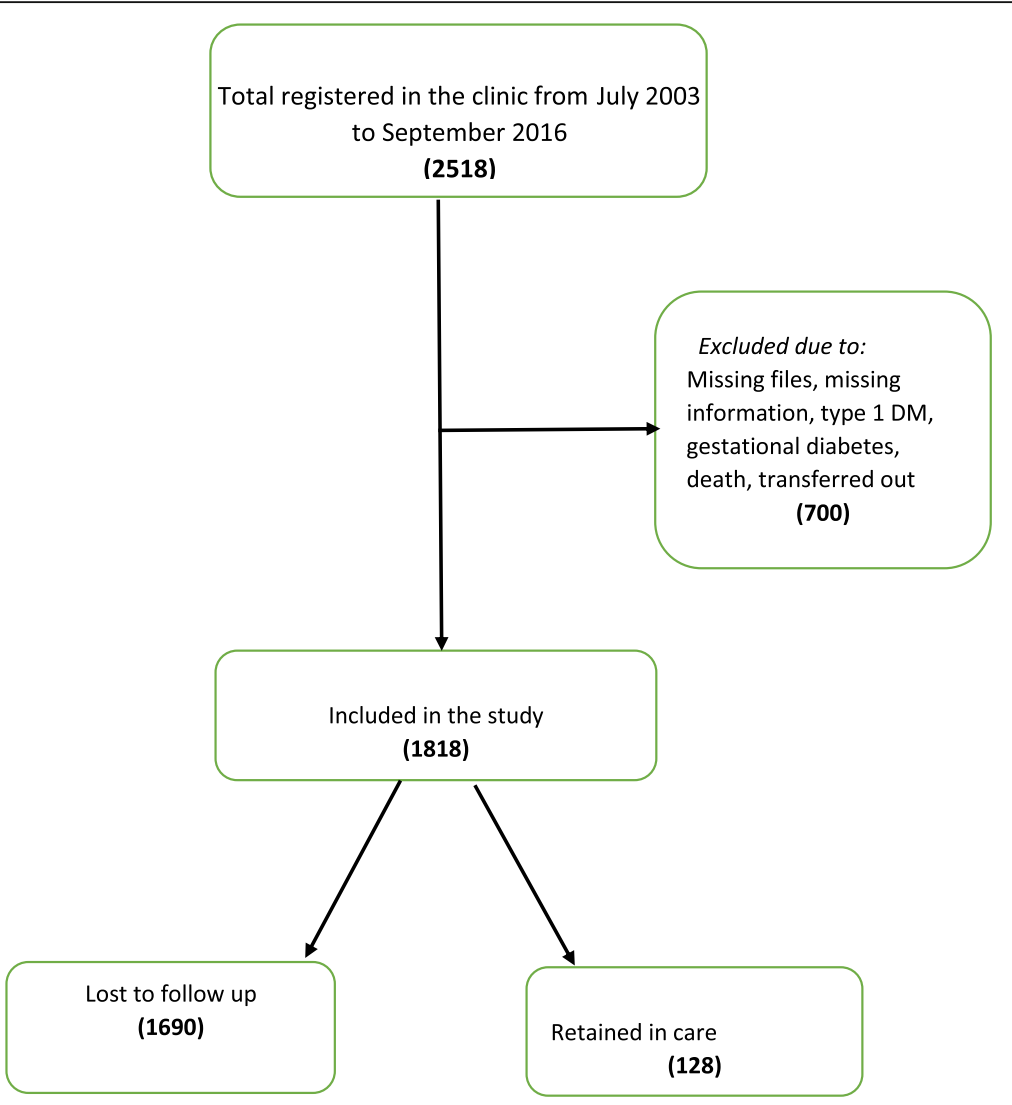

Fig. 1 Study organogram

\section{Discussion}

In this retrospective study, we found a high proportion of loss to follow up among patients with diabetes mellitus attending a diabetes clinic in a private not for profit urban hospital in Uganda. We found that male gender, having diabetic complications such as neuropathy and nephropathy, and using a triple therapy regimen significantly associated with LTFU. Retention in diabetes care was associated with older age, being in middle and upper socioeconomic status, being a non-smoker and being on a dual therapy regimen. We also found high rates of hypertension and a large number of patients did not achieve the recommended targets for optimal diabetes control.

Our LTFU proportion was much higher than that reported from developed countries which varied from 5.4 to $18 \%$ in Malaysia, $5.5 \%$ in German [13], 12\% in Nashville-Tennessee [14] and 46\% in Canada [15]. Similarly, our LTFU proportion was higher than that reported from Kenya which had a dropout rate of 31\% [22]. Our study was done in a private not for profit hospital where patients pay for their care and that could explain the high proportion of patients lost to follow up. Although the LTFU might be due to deaths being misclassified as LTFU the cost of medical care could have resulted in the majority of patients with diabetes mellitus selfrefering themselves to other public facilicties where care is free, without proper referral procedures. This is supported by the findings that those with middle and higher socioeconomic status and thus more able to meet the medical care costs were more likely to be retained compared to the lower socioecomic status. However since deaths and transfer outs were not recorded, the resultant misclassification might have led to a biased high estimate of the LTFU as high mortality rates among diabetes patients have previously been reported from some studies [27-29].

In our study, we found that male gender, was associated with loss to follow up, similar findings were reported by Chew et al. who analysed the diabetes mellitus registry in Malaysia [12]. Other chronic care treatment providers like HIV programs have also reported that males were associated with clinic non-attendance. Additionally, being on a triple therapy regimen and having had complications of diabetes mellitus like neuropathies and nephropathy were also associated with loss to follow up. However, if the patients with diabetes complications and those on triple therapy could have died, this could have possibly lead to a biased overestimate of LTFU. These findings are similar to those that were reported by Chew et al., in Malaysia and similar to other quantitative studies done in the United Kingdom and United States that showed 
Table 1 Baseline characteristics of patients retained and LTFU in a retrospective chart review study of patients with type 2 diabetes mellitus

\begin{tabular}{|c|c|c|c|c|}
\hline Variable Name & Category & Retained N (col \%) 128 (7\%) & LTFU N (col \%) 1690 (93\%) & Chi-Square $P$-value \\
\hline \multicolumn{5}{|l|}{ Socio-demographic characteristics } \\
\hline \multirow[t]{3}{*}{ Sex } & & & & 0.016 \\
\hline & Female & $88(69)$ & $978(58)$ & \\
\hline & Male & $40(31)$ & $712(42)$ & \\
\hline Median age (IQR) (years) & Age & $60(50-68)$ & $53(44-64)$ & $<0.001$ \\
\hline \multirow[t]{4}{*}{ Age group (years) } & & & & 0.001 \\
\hline & $19-44$ & $15(12)$ & $439(26)$ & \\
\hline & $45-64$ & $68(53)$ & $831(49)$ & \\
\hline & Above 64 & $45(35)$ & $420(25)$ & \\
\hline \multirow[t]{4}{*}{ Residence } & & & & 0.966 \\
\hline & Rural & $14(11)$ & $193(12)$ & \\
\hline & Peri-urban & $33(26)$ & $422(24)$ & \\
\hline & Urban & $81(63)$ & $1075(64)$ & \\
\hline \multirow[t]{4}{*}{ Education level } & & & & 0.23 \\
\hline & $<=$ Primary Education & $50(39)$ & $753(45)$ & \\
\hline & Secondary & $53(41)$ & $574(34)$ & \\
\hline & Post-Secondary & $25(20)$ & $363(21)$ & \\
\hline \multirow[t]{4}{*}{ Socioeconomic status } & & & & 0.107 \\
\hline & Lower & $22(17)$ & $408(24)$ & \\
\hline & Middle & $58(45)$ & $771(46)$ & \\
\hline & Upper & $48(38)$ & $511(30)$ & \\
\hline \multicolumn{5}{|l|}{ Life style characteristics } \\
\hline \multirow[t]{3}{*}{ Smoking } & & & & 0.19 \\
\hline & No & $119(93)$ & $1509(89)$ & \\
\hline & Yes & $9(7)$ & $181(11)$ & \\
\hline \multirow[t]{3}{*}{ Alcohol } & & & & 0.646 \\
\hline & No & $93(73)$ & $431(26)$ & \\
\hline & Yes & $35(27)$ & $1259(74)$ & \\
\hline \multicolumn{5}{|l|}{ DM treatment characteristics } \\
\hline \multirow[t]{3}{*}{ Life style alone } & & & & 0.176 \\
\hline & No & $127(99)$ & $1637(97)$ & \\
\hline & Yes & $1(1)$ & $53(3)$ & \\
\hline \multirow[t]{3}{*}{ Lifestyle and monotherapy } & & & & 0.03 \\
\hline & No & $106(83)$ & $1254(74)$ & \\
\hline & Yes & $22(17)$ & $436(26)$ & \\
\hline \multirow[t]{3}{*}{ Lifestyle and dual therapy } & & & & 0.006 \\
\hline & No & $40(31)$ & $740(44)$ & \\
\hline & Yes & $88(69)$ & $950(56)$ & \\
\hline \multirow[t]{3}{*}{ Lifestyle and triple therapy } & & & & 0.359 \\
\hline & No & $115(90)$ & $1557(92)$ & \\
\hline & Yes & $13(10)$ & $133(8)$ & \\
\hline \multirow[t]{2}{*}{ Lifestyle and combination injection therapy } & & & & 0.037 \\
\hline & No & $122(95)$ & $1514(90)$ & \\
\hline
\end{tabular}


Table 1 Baseline characteristics of patients retained and LTFU in a retrospective chart review study of patients with type 2 diabetes mellitus (Continued)

\begin{tabular}{|c|c|c|c|c|}
\hline Variable Name & Category & Retained N (col \%) 128 (7\%) & LTFU N (col \%) 1690 (93\%) & Chi-Square $P$-value \\
\hline & Yes & $6(5)$ & $176(10)$ & \\
\hline \multicolumn{5}{|l|}{ DM complications and comorbidities } \\
\hline \multirow[t]{3}{*}{ Neuropathy } & & & & $<0.001$ \\
\hline & No & $54(42)$ & $1141(68$ & \\
\hline & Yes & $74(58)$ & $549(32))$ & \\
\hline \multirow[t]{3}{*}{ Nephropathy } & & & & 0.005 \\
\hline & No & $114(89)$ & $1605(95)$ & \\
\hline & Yes & $14(11)$ & $85(5)$ & \\
\hline \multirow[t]{3}{*}{ Retinopathy } & & & & 0.01 \\
\hline & No & $94(73)$ & $1394(82)$ & \\
\hline & Yes & $34(27)$ & $296(18)$ & \\
\hline \multirow[t]{3}{*}{ Macroangiopathy } & & & & 0.003 \\
\hline & No & $120(94)$ & $1654(98)$ & \\
\hline & Yes & $8(6)$ & $36(2)$ & \\
\hline \multirow[t]{3}{*}{ Diabetic foot } & & & & 0.038 \\
\hline & No & $116(91)$ & $1604(95)$ & \\
\hline & Yes & $12(9)$ & $86(5)$ & \\
\hline \multirow[t]{3}{*}{ Hypoglycaemia } & & & & 0.095 \\
\hline & No & $122(95)$ & $1651(98)$ & \\
\hline & Yes & $6(5)$ & $39(2)$ & \\
\hline \multirow[t]{3}{*}{ Hypertension } & & & & 0.001 \\
\hline & No & $26(20)$ & $593(35)$ & \\
\hline & Yes & $102(80)$ & $1097(65)$ & \\
\hline \multirow[t]{3}{*}{ Erectile dysfunction ${ }^{a}$} & & & & $<0.001$ \\
\hline & No & $23(57)$ & $576(81)$ & \\
\hline & Yes & $17(43)$ & $136(19)$ & \\
\hline \multirow[t]{3}{*}{ Fasting plasma glucose (Mmol/l) } & & & & 0.955 \\
\hline & Controlled glycaemia & $35(27)$ & $466(28)$ & \\
\hline & Hyperglycaemia & $93(73)$ & $1224(72)$ & \\
\hline
\end{tabular}

$D M$ - Diabetes mellitus, ${ }^{a}$ Erectile dysfunction - (Not Applicable for 1066 females). Boldface means significant at $P$-value $<0.05$ for Tables $1 \& 2$

presence of neuropathy, low income, smoking and male sex being associated to loss to follow up.

\section{Study strengths}

To our understanding, this study is one of the first studies to evaluate diabetes care in a private not for profit health facility in Uganda focusing on patients' LTFU. Assessment of LTFU among patients with diabetes mellitus is important as it is directly related to attainment of optimal glyceamic control and prevention of complications of diabetes. Secondly understanding factors associated with LTFU from care can provide valuable information for the improvement of care. The use of patients routine care data for this review has provided us with a large sample size which would not have been feasible if otherwise.

\section{Study limitations}

As with most clinic care records, the quality of data recorded is usually less satisfactory, and in our case, the incomplete data on referrals and deaths might have biased our estimated LTFU. Additionally this data from an operational program was initially not designed for research purposes, not validated, had no quality checks done for completeness and plausibility, and we were only able to look at a limited number of variables documented in the patient's charts. We also have little understanding of the health system and patient related reasons for drop out of care which can only be 
Table 2 Multivariable analysis of predictors of patients lost to follow-up

\begin{tabular}{|c|c|c|c|c|c|c|}
\hline Variable Name & Category & $\begin{array}{l}\text { LTFU } \\
\mathrm{N}=1690 \\
\mathrm{n}(\mathrm{col} \%)\end{array}$ & uHR $95 \% \mathrm{Cl}$ & P-value & aHR 95\%Cl & $P$-value \\
\hline \multicolumn{7}{|c|}{ Socio-demographic Characteristics } \\
\hline \multicolumn{7}{|l|}{ Sex } \\
\hline & Female & $712(42)$ & Reference & & & \\
\hline & Male & $978(58)$ & $1.27(1.15-1.40)$ & $<0.001$ & $1.17(1.06-1.30)$ & 0.002 \\
\hline \multicolumn{7}{|l|}{ Age group } \\
\hline & $19-44$ & $439(26)$ & Reference & & & \\
\hline & $45-64$ & $831(49)$ & $0.73(0.65-0.83)$ & $<0.001$ & $0.83(0.74-0.94)$ & 0.003 \\
\hline & Above 64 & $420(25)$ & $0.63(0.55-0.72)$ & $<0.001$ & $0.78(0.67-0.90)$ & 0.001 \\
\hline \multicolumn{7}{|c|}{ Socioeconomic statu } \\
\hline & Lower & $408(24)$ & Reference & & & \\
\hline & Middle & $771(46)$ & $0.88(0.78-0.99)$ & 0.041 & $0.83(0.74-0.94)$ & 0.003 \\
\hline & Upper & $511(30)$ & $0.88(0.77-0.99)$ & 0.046 & $0.83(0.73-0.95)$ & 0.006 \\
\hline \multicolumn{7}{|c|}{ Life Style Characterisitcs } \\
\hline \multicolumn{7}{|l|}{ Smoking } \\
\hline & No & 1509 (89) & Reference & & & \\
\hline & Yes & $181(11)$ & $1.26(1.08-1.47)$ & 0.003 & $1.22(1.04-1.44)$ & 0.016 \\
\hline \multicolumn{7}{|c|}{ DM Treatment characteristics } \\
\hline \multicolumn{7}{|c|}{ Lifestyle and monotherapy } \\
\hline & No & $1254(74)$ & Reference & & & \\
\hline & Yes & $436(26)$ & $1.34(1.20-1.49)$ & $<0.001$ & $1.02(0.86-1.22)$ & 0.808 \\
\hline \multicolumn{7}{|c|}{ Lifestyle \& dual therapy } \\
\hline & No & $740(44)$ & Reference & & & \\
\hline & Yes & $950(56)$ & $0.81(0.74-0.90)$ & $<0.001$ & $0.79(0.67-0.94)$ & 0.006 \\
\hline \multicolumn{7}{|c|}{ Lifestyle \& triple therapy } \\
\hline & No & $1557(92)$ & Reference & & & \\
\hline & Yes & $133(8)$ & $0.79(0.66-0.95)$ & 0.01 & $0.77(0.61-0.97)$ & 0.028 \\
\hline
\end{tabular}

DM Complications and comorbidities

Hypertension

$\begin{array}{ll}\text { No } & 593(35) \\ \text { Yes } & 1097(65)\end{array}$

Reference

$0.71(0.65-0.79)$

$<0.001$

$0.90(0.81-1.01)$

0.07

Neuropathy

No $\quad 1141(68)$

Reference

0.64 (0.57-0.70)

$<0.001$

$0.72(0.65-0.81)$

$<0.001$

Nephropathy

$\begin{array}{ll}\text { No } & 1605(95) \\ \text { Yes } & 85(5)\end{array}$

Reference

$0.54(0.43-0.67)$

$<0.001$

$0.57(0.45-0.71)$

$<0.001$

Retinopathy

$\begin{array}{ll}\text { No } & 1394(82) \\ \text { Yes } & 296(18)\end{array}$

Reference

$0.70(0.62-0.80)$

$<0.001$

$0.89(0.78-1.02)$

0.101

Macroangiopathy

$\begin{array}{ll}\text { No } & 1654(98) \\ \text { Yes } & 36(2)\end{array}$

Reference

0.75 (0.54-1.05)

0.093

$0.91(0.65-1.27)$

Diabetic foot 
Table 2 Multivariable analysis of predictors of patients lost to follow-up (Continued)

\begin{tabular}{|c|c|c|c|c|c|c|}
\hline Variable Name & Category & $\begin{array}{l}\text { LTFU } \\
\mathrm{N}=1690 \\
\mathrm{n}(\mathrm{col} \%)\end{array}$ & uHR 95\%Cl & P-value & aHR 95\%Cl & $P$-value \\
\hline & No & $1604(95)$ & Reference & & & \\
\hline & Yes & $86(5)$ & $0.68(0.55-0.85)$ & 0.001 & $0.82(0.65-1.02)$ & 0.072 \\
\hline \multicolumn{7}{|c|}{ Hypoglycaemia } \\
\hline & No & 1651 (98) & Reference & & & \\
\hline & Yes & $39(2)$ & $0.74(0.54-1.01)$ & 0.061 & $0.79(0.58-1.09)$ & 0.157 \\
\hline
\end{tabular}

Boldface means significant at $P$-value $<0.05$ for Tables $1 \& 2$

answered by a purposively designed qualitative study. Due to the changes in the general economic status in the country, the patients economic status might have changed over the 13 years duration of the study from what it was at registration in the clinic. Although rural to urban migration is common among those searching for jobs, urban to rural migration also occurs among those who find urban employment and survival hard to obtain, which might have contributed to LTFU. The method used by the health facility to classify socioeconomic status and residence were not standardised and could have changed over the years.

\section{Conclusion}

Loss to follow up in a diabetes mellitus care has serious implications for patients with diabetes mellitus due to the subsequent complications and resultant morbidity, mortality and management costs as well as the disease burden on the health system. Our findings warrant stengthening patient follow up in diabetes care and conducting interventional studies targeting the identified associated risk factors for LTFU.

\section{Abbreviations}

aHR: Adjusted Hazard Ratio; Cl: Confidence intervals; H3A: Human Heredity and Health in Africa; HbA1c: Glycated haemoglobin; HRs: Hazard Ratios; Km: Kilometer; LDL-C: Low Density Lipoprotein cholesterol; LRT: Likelihood ratio tests; LTFU: Loss to follow up; REC: Research and Ethics Committee; SES: Socioeconomic Status; uHR: Unadjusted hazard ratio; UNCST: Uganda National Council for Science and Technology; UVRI: Uganda Virus Research Institute

\section{Acknowledgements}

We acknowledge the contribution of H3A Type 2 Diabetes study participants, the H3A Type 2 Diabetes study team, and staff of St. Francis Hospital Nsambya and the MRC/UVRI and LSHTM Uganda Research Unit Statistics section

The H3A Type 2 Diabetes study team

Clara Wekesa, Salome Tino, Bengo Samuel, Kigongo Aisha, Rose Nabwatwo, Anthony Makhoba, Raymond Mwebaze, Onesmus Kamacooco, Edward Ddumba, Billy N. Mayanja, Pontiano Kaleebu, Rob Newton and Moffat Nyerinda.

\section{Authors' contributions}

All authors conceived and designed the study. TS, AM, RM, SB, RN1, AK participated in data collection and OK conducted the data analysis. TS, CW $\mathrm{BNM}, \mathrm{MN}$, interpreted and wroted the original manuscript draft; ED, PK and RN2 revised the initial draft and all authors revised and approved the final version of the paper.

\section{Funding \\ There was no separate funding for this descriptive retrospective chart review} study.

\section{Availability of data and materials}

Data will not be shared publicly due to the data sharing policy of the MRC/ UVRI and London School of Hygiene and Tropical Medicine Uganda Research Unit, which requires a prior data sharing agreement. However, a full data set containing the data supporting the study findings in this report can be obtained from the Unit Director, by email to: mrc@mrcuganda.org or the corresponding author. More clarification on this can be accessed through this website: https://www.mrcuganda.org/publications/data-sharingpolicy

\section{Ethics approval and consent to participate}

This study was nested within the bigger H3A Diabetes Multi-centre study whose main aim was to assess the prevalence, environmental and genetic determinants of type 2 diabetes in sub-Saharan Africa. This study received approval form Uganda Virus Research Institute Research and Ethics Committee, reference number -UVRI REC 456, the Uganda National Council for Science and Technology, reference number - UNCST HS 1671 and administrative clearance was obtained from the Research Ethics Committee of St Francis Hospital Nsambya. Patients names were not included in the data extraction forms and the study was conducted in accordance with ethical principles and confidentiality was ensured throughout the study.

\section{Consent for publication}

Not applicable.

\section{Competing interests}

The authors declare that they have no competing interests.

\section{Author details}

${ }^{1}$ MRC/UVRI and LSHTM Uganda Research Unit, P.O. Box 49, Entebbe, Uganda. ${ }^{2}$ St. Francis Hospital Nsambya, P. O. Box, 7146 Kampala, Uganda. ${ }^{3}$ London School of Hygiene and Tropical Medicine, Keppel Street, London WC1E 7HT, United Kingdom. ${ }^{4}$ Department of Health Sciences, University of York, Heslington, York YO10 5DD, United Kingdom.

Received: 1 April 2019 Accepted: 9 August 2019

Published online: 23 August 2019

\section{References}

1. Ogurtsova K, et al. IDF diabetes atlas: global estimates for the prevalence of diabetes for 2015 and 2040. Diabetes Res Clin Pract. 2017;128:40-50.

2. Goldenberg RL1, McClure EM, Bhutta ZA, Belizán JM, Reddy UM, Rubens CE, Mabeya H, Flenady V, Darmstadt GL. Lancet's Stillbirths Series steering committee. Stillbirths: the vision for 2020. Lancet. 2011;377(9779):1798-805.

3. Hu FB. Globalization of diabetes. Diabetes Care. 2011;34(6):1249.

4. Dagenais GR, et al. Variations in diabetes prevalence in low-, middle-, and high-income countries: results from the prospective urban and rural epidemiological study. Diabetes Care. 2016;39(5):780

5. Chiwanga FS, et al. Urban and rural prevalence of diabetes and pre-diabetes and risk factors associated with diabetes in Tanzania and Uganda. Glob Health Action. 2016;9(1):31440. 
6. Sahadew N, Singaram VS, Brown S. Distribution, incidence, prevalence and default of patients with diabetes mellitus accessing public healthcare in the 11 districts of KwaZulu-Natal, South Africa. South Afr Med J. 2016;106(4):389-93.

7. Group, U.P.D.S. Intensive blood-glucose control with sulphonylureas or insulin compared with conventional treatment and risk of complications in patients with type 2 diabetes (UKPDS 33). Lancet. 1998;352(9131):837-53.

8. Control D, C.T.R. Group. The effect of intensive treatment of diabetes on the development and progression of long-term complications in insulindependent diabetes mellitus. N Engl J Med. 1993;1993(329):977-86.

9. Chawla, R. Complications of Diabetes. Jaypee Brothers Medical Pub; 1st edition (April 30, 2012) Available at: https://www.amazon.com/ Complications-Diabetes-Rajeev-M-D-Chawla/dp/935025512X. Accessed 12 Nov 2018.

10. Ngwenya BT, van Zyl DG, Webb EM. Factors influencing non-attendance of clinic appointments in diabetic patients at a Gauteng hospital in 2007/2008. J Endocrinol Metab Diabetes S Afr. 2009;14(2):106-10.

11. Nathan DM, et al. The effect of intensive treatment of diabetes on the development and progression of long-term complications in insulindependent diabetes mellitus. N Engl J Med. 1993;329(14):977-86.

12. Chew BH, et al. Predictive factors of follow-up non-attendance and mortality among adults with type 2 diabetes mellitus- an analysis of the Malaysian diabetes registry 2009. Curr Diabetes Rev. 2015;11(2):122-31.

13. Fullerton $B$, et al. Predictors of dropout in the German disease management program for type 2 diabetes. BMC Health Serv Res. 2012;12(1):8

14. Graber AL, et al. Dropout and relapse during diabetes care. Diabetes Care. 1992:15(11):1477-83

15. Malcolm JC, et al. Into the abyss: diabetes process of care indicators and outcomes of defaulters from a Canadian tertiary care multidisciplinary diabetes clinic. BMC Health Serv Res. 2013;13(1):303.

16. Nielsen KM, et al. Cardiac rehabilitation: health characteristics and socio-economic status among those who do not attend. Eur J Pub Health. 2008;18(5):479-83.

17. Masuda $Y$, et al. Personal features and dropout from diabetic care. Environ Health Prev Med. 2006;11(3):115-9.

18. Dyer PH, et al. Factors associated with clinic non-attendance in adults with type 1 diabetes mellitus. Diabet Med. 1998;15(4):339-43.

19. Jacobson AM, et al. Clinic attendance and glycemic control. Study of contrasting groups of patients with IDDM. Diabetes Care. 1991;14(7):599-601.

20. Archibald LK, Gill GV. Diabetic clinic defaulters - who are they and why do they default? Pract Diabetes Int. 1992;9(1):13-4

21. Kawahara $\mathrm{R}$, et al. Dropout of young non-insulin-dependent diabetics from diabetic care. Diabetes Res Clin Pract. 1994;24(3):181-5.

22. Sobry A, et al. Caseload, management and treatment outcomes of patients with hypertension and/or diabetes mellitus in a primary health care programme in an informal setting. Tropical Med Int Health. 2014;19(1):47-57.

23. Lee RRS, et al. Factors affecting follow-up non-attendance in patients with type 2 diabetes mellitus and hypertension: a systematic review. Singap Med J. 2019;60(5):216-23.

24. St. Francis Hospital Nsambya http://www.nsambyahospital.or.ug. Accessed on 24 October 2018.

25. Kibirige D, et al. Suboptimal glycaemic and blood pressure control and screening for diabetic complications in adult ambulatory diabetic patients in Uganda: a retrospective study from a developing country. J Diabetes Metab Disord. 2014;13:40

26. Mugisha F, et al. The two faces of enhancing utilization of health-care services: determinants of patient initiation and retention in rural Burkina Faso. Bull World Health Organ. 2004;82(8):572-9.

27. Pildava S, Strēle I, Briǵis $\mathrm{G}$. The mortality of patients with diabetes mellitus in Latvia 2000-2012. Medicina. 2014;50(2):130-6.

28. Jung HH, Park Jl, Jeong JS. Incidence of diabetes and its mortality according to body mass index in south Koreans aged $40-79$ years. Clin Epidemiol. 2017:9:667-78.

29. Zhu M, et al. Mortality rates and the causes of death related to diabetes mellitus in Shanghai Songjiang District: an 11-year retrospective analysis of death certificates. BMC Endocr Disord. 2015;15:45.

\section{Publisher's Note}

Springer Nature remains neutral with regard to jurisdictional claims in published maps and institutional affiliations.

Ready to submit your research? Choose BMC and benefit from:

- fast, convenient online submission

- thorough peer review by experienced researchers in your field

- rapid publication on acceptance

- support for research data, including large and complex data types

- gold Open Access which fosters wider collaboration and increased citations

- maximum visibility for your research: over $100 \mathrm{M}$ website views per year

At BMC, research is always in progress.

Learn more biomedcentral.com/submissions 